\title{
A Rare Presentation of Primary Antiphospholipid Syndrome
}

\author{
Panduranga Prashanth, Mohammed Mukhaini, Abdulla Riyami
}

\section{Abstract}

This case presents a young patient with myocardial infarction, in-situ thrombosis of left anterior descending coronary artery and right common-iliac artery due to primary antiphospholipid syndrome. This report discusses the relationship between antiphospholipid antibodies and coronary artery disease along with management of this rare condition.

Prashanth P, et al. OMJ. 24, 300-302 (2009); doi:10.5001/omj.2009.61

\section{Introduction}

ntiphospholipid syndrome (APS) is a systemic autoimmune disorder characterized by a combination of arterial and/or venous thrombosis, and recurrent fetal loss, often accompanied by a thrombocytopenia, and elevated titers of antiphospholipid antibodies (aPL), namely, the lupus anticoagulant (LA) and/ or anticardiolipin antibodies (aCL). The syndrome occurs in isolation (Primary Antiphospholipid Syndrome) or in association with connective tissue diseases (Secondary Antiphospholipid Syndrome), particularly systemic lupus erythematosus. ${ }^{1}$ Cardiac manifestations in APS may include myocardial infarction (MI), valve thickening/dysfunction, angina, cardiomyopathy, vegetations, coronary bypass graft thrombosis, intracardiac thrombus and pulmonary embolism/hypertension. ${ }^{2} \mathrm{MI}$ can be the first manifestation of APS, although it is not common.

This case present a young patient with MI, in-situ thrombosis of the left anterior descending coronary artery and right commoniliac artery due to primary APS.

\section{Case Report}

A 23-year-old fit Omani male was referred for coronary angiography. Three months prior, he was presented at a regional hospital with chest pain. His electrocardiogram at the time showed deep $\mathrm{T}$ wave inversion in anterior leads along with elevated cardiac enzymes. He was diagnosed to have non-ST elevation MI and was treated with aspirin, heparin, nitrates and atenolol. There was no history of drug abuse, smoking, hypertension, diabetes or a family history of coronary artery disease. He was asymptomatic since his infarction and his clinical examination was normal except for absent right femoral pulse with no signs of leg ischemia. His medications included aspirin and atenolol. His routine blood tests along with platelet count and fasting lipids were normal except for prolonged activated partial thromboplastin time (aPTT) (48.4 sec [n-27.2-39.1]), which did not correct after mixing with plateletpoor plasma from a normal donor.
From the Department of Cardiology, Royal Hospital, Muscat, Sultanate of Oman.

Received: 25 Jun 2009

Accepted: 27 Jul 2009

Address correspondence and reprint requests to: Dr.Prashanth $P$, Department of Cardiology, Royal Hospital, PB 1331, Muscat-111, Sultanate of Oman.

E-mail address:prashanthp_69@yahoo.co.in
Echocardiogramshowedhypokineticapexwithejection fraction of $65 \%$, normal valves and no thrombus. Coronary angiography performed from the left femoral approach revealed an occluded left anterior descending (LAD) artery with intracoronary thrombus loading proximally with TIMI 0 flow (absent flow) (Fig. 1A, 1B, $2 \mathrm{~A}$ arrowheads). Distal LAD was faintly filled by collaterals. His lower abdominal aortogram showed totally occluded right common iliac artery and proximal right internal iliac artery, with distal perfusion by collaterals (Fig. 2B arrowheads).

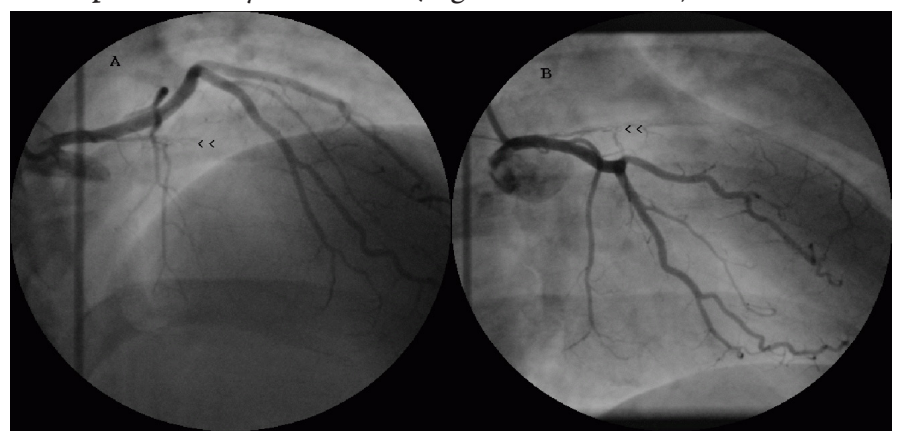

Figure 1: Coronary angiogram in RAO cranial view (A) and RAO caudal view (B) showing totally occluded left anterior descending artery with absent flow and multiple filling defects (white streaks) suggesting intracoronary thrombus (arrowheads) in a patient with primary antiphospholipid antibody syndrome.

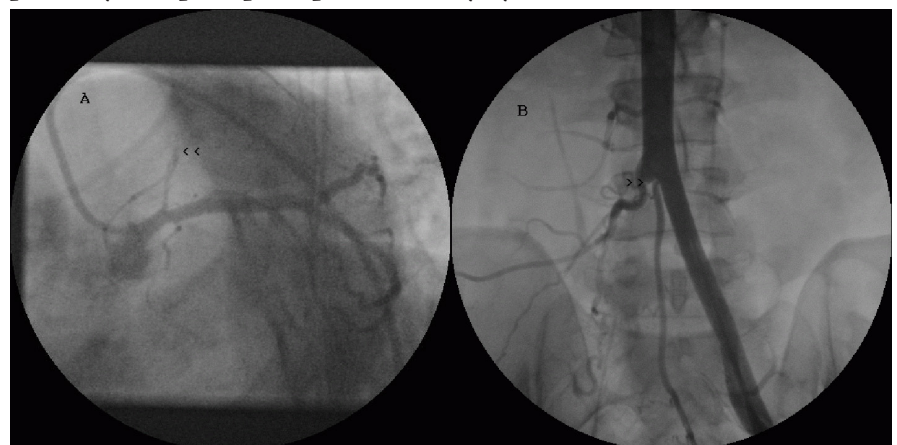

Figure 2: Coronary angiogram in LAO caudal view (A) showing totally occluded left anterior descending artery with absent flow (arrowheads). Lower abdominal aortogram (B) showing totally occluded right common iliac artery and proximal right internal iliac artery (arrowheads). 
The patient was suspected to have APS and further blood tests were performed. He denied history of fever, arthralgia or rash. He did not have a risk factors for HIV. His thrombophilia screening, anti-nuclear antibody and extractable nuclear antigens were negative. His LA was positive along with elevated $\operatorname{IgG}(22.6$ $\mathrm{U} / \mathrm{ml}(\mathrm{n}-[0.1-15])$ aCL antibodies with normal IgM and anti- $\beta-2$ glycoprotein-1 IgG/IgM antibodies. He was warfarinised [target international normalized ratio (INR) 3-4] for three months without recurrent thrombotic events and was asymptomatic. His repeat LA after three months was positive, but his aCL antibodies were normalized. Repeat coronary angiogram performed after three months showed TIMI 3 flow (complete flow) with diffuse intracoronary organized clots all along LAD and diagonal branch (seen as intraluminal filling defects viz. white streaks) (Fig. 3, 4 arrowheads). The LAD was small in size compared to left circumflex artery, but there was no stenosis or dissection. His right common iliac artery was totally occluded as before. He was advised lifelong warfarin and was doing well after one year of follow-up.

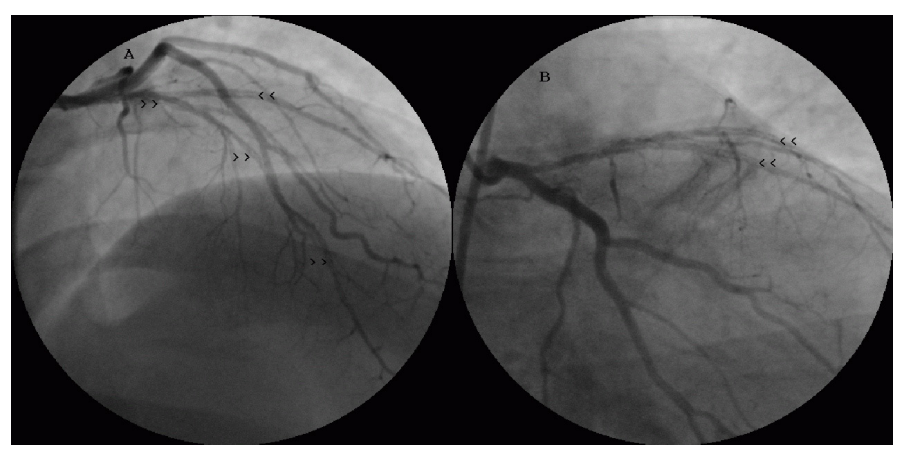

Figure 3: Follow-up coronary angiogram in RAO cranial view (A) and RAO caudal view (B) showing normal left anterior descending artery flow with multiple intraluminal filling defects suggesting organized thrombus all along the artery and also in diagonal artery (arrowheads).

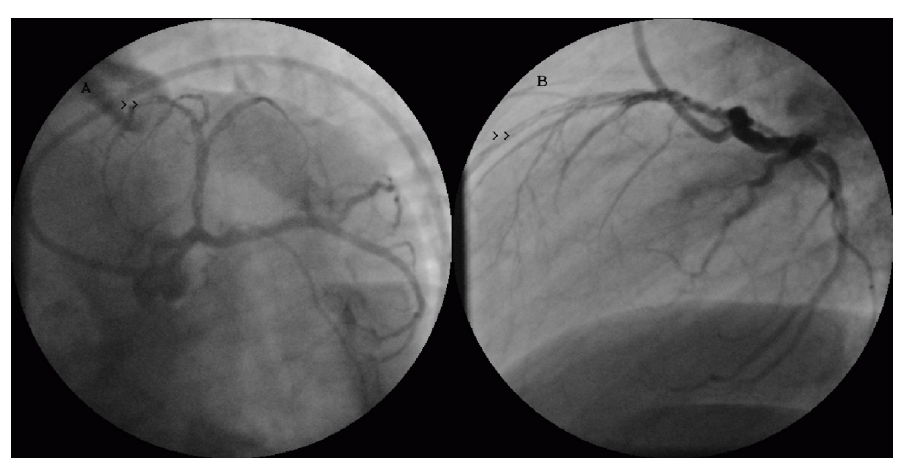

Figure 4: Follow-up coronary angiogram in LAO caudal view (A) and left lateral view (B) showing multiple intracoronary thrombi (arrowheads).

\section{Discussion}

Primary APS is largely seen in young women with male to female ratio of $3.5: 1$ and the age of first thrombosis in APS is between 15 and 50 years. ${ }^{2}$ Deep vein thrombosis, pulmonary thromboembolism, and stroke are the most common manifestations in antiphospholipid syndrome. The thrombotic episodes are often multiple and repeated, but this syndrome is rarely initiated in the coronary arteries. Acute MI can occur with normal coronaries with or without thrombus seen at the time of angiography. ${ }^{3} \mathrm{MI}$ in APS occurs in young patients with similar clinical manifestations as in general population. In the Euro-Phospholipid project, $2.8 \%$ initially presented with $\mathrm{MI}^{2}$

In a series of over 800 patients with APS, Davies et al. noted that less than $1 \%$ of the patients were presented with $\mathrm{MI}^{3}$ After MI, up to $15 \%$ of patients had aPL antibodies compared with around $4.4 \%$ in the control group, but they were absent on repeat testing during recovery. ${ }^{4}$ Following $\mathrm{MI}$, aPL antibodies are a risk factor for recurrent events and also, aCL antibodies in healthy men have been shown to confer a twofold increased relative risk for $\mathrm{MI}^{5,6}$

In APS, aPL antibodies can cause thrombosis in normal vessels (in-situ thrombosis), lead to accelerated atherosclerosis and in some individuals, transient aPL antibodies may arise at the time of MI because of vascular injury and exposure of neoantigens. ${ }^{3}$ The possible mechanisms of thrombosis in APS include effects of aPL antibodies on platelet membranes, on endothelial cells and on clotting components such as prothrombin, protein $\mathrm{C}$ and protein $\mathrm{S}$ leading to platelet aggregation and clot formation. In patients with APS, the aPL antibodies persist for years, possibly for a lifetime. Recently, circulating procoagulant microparticles were found to contribute to thrombotic propensity in patients with APS. ${ }^{8}$

The diagnostic criteria include a combination of clinical criteria (vascular thrombosis or pregnancy morbidity) and laboratory criteria ( LA and/or aCL IgG or IgM antibodies or anti-2 glycoprotein-1 IgG or IgM antibodies) at least 12 weeks apart. ${ }^{1}$ In the study patient, antibodies were still high six-months after the myocardial infarction and fulfilling the Sapporo criteria. ${ }^{1}$

Management of patients with MI in APS is similar to other patients, and thrombolysis/primary stenting has been found to be successful in patients presenting with ST elevation MI., ${ }^{9,10}$ In the study patient, angioplasty or stenting were not performed because it was apparent that most of the patients have normal coronaries with severe clot burden and intervention would have led to more complications and recurrent stent thrombosis. The risk of recurrent thrombosis in patients with APS is high and the recommended treatment is a high-dose oral anticoagulation with target INR 
of 2-3 for venous and 3-4 for arterial thromboembolism as it is thought that arterial thrombosis is caused by more potent antibodies, with a higher recurrence rate. ${ }^{11,12}$

\section{Conclusion}

In conclusion, young patients presenting with vascular thrombosis in two different territories, as well as those presenting with myocardial infarction and normal coronaries with or without intracoronary thrombus should be investigated for APS and managed with long-term anticoagulation.

\section{Acknowledgements}

The authors reported no conflict of interest and no funding was received on this work.

\section{References}

1. Miyakis S, Lockshin MD, Atsumi T, Branch DW, Brey RL, Cervera R, et al. International consensus statement on an update of the classification criteria for definite antiphospholipid syndrome (APS). J Thromb Haemost 2006 Feb;4(2):295-306.

2. Cervera R, Piette JC, Font J, Khamashta MA, Shoenfeld Y, Camps MT, et al; Euro-Phospholipid Project Group. Antiphospholipid syndrome: clinical and immunologic manifestations and patterns of disease expression in a cohort of 1,000 patients. Arthritis Rheum 2002 Apr;46(4):1019-1027.

3. Davies JO, Hunt BJ. Myocardial infarction in young patients without coronary atherosclerosis: assume primary antiphospholipid syndrome until proved otherwise. Int J Clin Pract 2007 Mar;61(3):379-384.
4. Vaarala O. Antiphospholipid antibodies and myocardial infarction. Lupus 1998;7:132-134.

5. Bili A, Moss AJ, Francis CW, Zareba W, Watelet LF, Sanz I; Thrombogenic Factors and Recurrent Coronary Events Investigators. Anticardiolipin antibodies and recurrent coronary events: a prospective study of 1150 patients. Thrombogenic Factors, and Recurrent Coronary Events Investigators. Circulation 2000 Sep;102(11):1258-1263.

6. Vaarala $\mathrm{O}$, Mänttäri M, Manninen V, Tenkanen L, Puurunen M, Aho $\mathrm{K}$, et al. Anti-cardiolipin antibodies and risk of myocardial infarction in a prospective cohort of middle-aged men. Circulation 1995 Jan;91(1):23-27.

7. Hughes GR. The antiphospholipid syndrome: ten years on. Lancet 1993 Aug;342(8867):341-344.

8. Morel O, Jesel L, Freyssinet JM, Toti F. Elevated levels of procoagulant microparticles in a patient with myocardial infarction, antiphospholipid antibodies and multifocal cardiac thrombosis. Thromb J 2005 Oct;3:15.

9. Ho YL, Chen MF, Wu CC, Chen WJ, Lee YT. Successful treatment of acute myocardial infarction by thrombolytic therapy in a patient with primary antiphospholipid antibody syndrome. Cardiology 1996 JulAug;87(4):354-357.

10. Badak O, Güneri S, Kirimli O, Göldeli O, Aslan O, Ozsan H. Primary stenting in a patient with acute myocardial infarction and primary antiphospholipid syndrome. J Invasive Cardiol 2002 Apr;14(4):194-197.

11. Lim W, Crowther MA, Eikelboom JW. Management of antiphospholipid antibody syndrome: a systematic review. JAMA 2006 Mar;295(9):10501057.

12. Khamashta MA, Hunt BJ. Moderate dose oral anticoagulant therapy in patients with the antiphospholipid syndrome? No. J Thromb Haemost 2005 May;3(5):844-845. 